\title{
Determining regionally applicable economic values for coastal habitats and their use in evaluating the cost effectiveness of regional conservation actions: the example of mangroves, in the South China Sea
}

\begin{abstract}
This paper outlines the process of: assembling an empirical data set relating to the values of resource ógoods and services1ôderived from coastal habitats bordering the South China Sea; standardising these data as production values per hectare per annum; converting local currencies to US dollars; and converting these values to a standard year (2007) by means of the consumer price index. In order to address the problem of the wide variation in prices within one country, the data were weighted to determine a óWeighted Mean National Valueô that reflected both the prices for the same resource at each location and the ótockôof that resource at the same locations. This results in a national value that reflects the totality of the national stock rather than being a simple arithmetic average of all values. The determination of weighted mean regional values was undertaken in a similar manner to the computation of weighted mean national values but using data and information concerning the total stock (or area) in each country and the weighted mean national values. These weighted regional mean values were subsequently used in a cost benefit analysis of actions to conserve regional coastal habitats.

What has resulted from this work is a standardised method for calculating national and regional weighted mean values of resource ógoods and servicesôthat can be applied more widely in handling and manipulating economic valuation data from multiple locations across any time span. The method can be applied in any region where multiple currencies, varying exchange rates and widespread inter-location variations in farm gate prices are found. The specific targets of the revised Strategic Action Plan for the South China Sea have been valued or, more specifically, the incremental benefit derived from achieving the SAP target has been valued. The values saved by achieving the targets are then compared with the costs of implementing the actions defined in the regional SAP through a cost benefit analysis.
\end{abstract}

Keyword: Coastal resources; Cost-benefit analysis; Resource values 